\title{
Fitness of F1 hybrids between 10 maternal wild soybean populations and transgenic soybean
}

\author{
Jin Yue Liu $\cdot$ Ze Wen Sheng $\cdot$ Yu Qi Hu $\cdot$ Qi Liu · Sheng Qiang • \\ Xiao Ling Song $(\mathbb{D} \cdot$ Biao Liu
}

Received: 27 October 2020/ Accepted: 8 December 2020/Published online: 5 January 2021

(C) The Author(s) 2021

\begin{abstract}
The releasing of transgenic soybeans (Glycine $\max (\mathrm{L}$.) Merr.) into farming systems raises concerns that transgenes might escape from the soybeans via pollen into their endemic wild relatives, the wild soybean (Glycine soja Sieb. et Zucc.). The fitness of F1 hybrids obtained from 10 wild soybean populations collected from China and transgenic glyphosate-resistant soybean was measured without weed competition, as well as one JLBC-1 F1 hybrid under weed competition. All crossed seeds emerged at a lower rate from 13.33-63.33\%. Compared with those of their wild progenitors, most F1 hybrids were shorter, smaller, and with decreased aboveground dry biomass, pod number, and 100-seed weight. All F1
\end{abstract}

Jin Yue Liu, Ze Wen Sheng, and Yu Qi Hu should be considered as joint first authors

Supplementary information The online version of this article (https://doi.org/10.1007/s11248-020-00230-x) contains supplementary material, which is available to authorized users.

J. Y. Liu · Z. W. Sheng · Y. Q. Hu ·

Q. Liu $\cdot$ S. Qiang $\cdot$ X. L. Song $(\bowtie) \cdot$ B. Liu

Weed Research Laboratory, College of Life Sciences,

Nanjing Agricultural University, Nanjing 210095,

Jiangsu Province, China

e-mail: sxl@njau.edu.cn

B. Liu

Ministry of Ecology and Environment, Nanjing Institute of Environmental Sciences, Nanjing 210042, People's

Republic of China hybrids had lower pollen viability and filled seeds per plant. Finally, the composite fitness of nine F1 hybrids was significantly lower. One exceptional F1 hybrid was IMBT F1, in which the composite fitness was 1.28 , which was similar to that of its wild progenitor due to the similarities in pod number, increased aboveground dry biomass, and 100-seed weight. Under weed competition, plant height, aboveground dry biomass, pod number per plant, filled seed number per plant, and 100-seed weight of JLBC-1 F1 were lower than those of the wild progenitor JLBC-1. JLBC-1 F1 hybrids produced 60 filled seeds per plant. Therefore, F1 hybrids could emerge and produce offspring. Thus, effective measures should be taken to prevent gene flow from transgenic soybean to wild soybean to avoid the production F1 hybrids when releasing transgenic soybean in fields in the future.

Keywords Transgenic soybean · Wild soybean · F1 hybrid $\cdot$ Fitness $\cdot$ Gene flow

\section{Introduction}

The cultivation area of transgenic soybeans have considerably increased since their commercial release in 1996. In 2018, transgenic soybeans were planted on 95.9 million hectare, reaching their highest level of adoption worldwide, covering $50 \%$ of the global 
biotech crop area, and $78 \%$ of the global soybean area (James 2019). Herbicide resistance, individually or stacked with insect resistance, has consistently been used as a dominant trait in soybeans. In 2017, herbicide-resistant soybeans accounted for $77 \%$ of the global biotech soybean area (James 2018). Although transgenic soybeans have not yet been commercially released in China, 17 transgenic soybeans were awarded safety certificates to allow them to be imported as raw material for processing from 2004, and 16 of these soybeans remain valid (http:// www.moa.gov.cn/ztzl/zjyqwgz/spxx/). Since 2012, $80 \%$ of consumed soybeans have been imported, reaching 88.03 million tons in 2018 (http://data.stats. gov.cn), most of which were herbicide-resistant soybeans. Meanwhile, domestic transgenic soybeans have also been developed under governmental support. On January 21, 2020, China's Ministry of Agriculture issued a biosafety certificate for production and field planting in the south of China of the glyphosate-resistant transgenic soybean SHZD32-01 developed by Shanghai Jiaotong University, representing a first step toward commercialized production of transgenic soybeans in China.

The release of transgenic soybeans to farming systems raises great concern that transgenes might escape from GM soybeans via pollen into their endemic wild relative, the wild soybean (Glycine soja Sieb. et Zucc.) (Kuroda et al. 2006; Yoshimura et al. 2011; Goto et al. 2017). Wild soybean ( $G$ genome, $2 \mathrm{n}=40$ ), the same genus as the cultivated soybean (Glycine $\max$ (Linn.) Merr.), is the progenitor of soybean and is extensively distributed in the Far East of Russia, the Korean peninsula, China, and Japan (Wang and Takahata 2007). Wild soybeans are an integral part of soybean genetic resources and are important for research on the origin and evolution of soybeans (Stupar 2010; Li et al. 2009, 2010; Akpertey et al. 2014). In China, wild soybeans are widely geographically distributed, almost in all soybean growing areas except for Hainan province, and they grow in diverse habitats even around farmland (Dong et al. 2001; Wang et al. 2017). Introgression from transgenic soybeans to wild soybeans may be happening.

Cultivated and wild soybeans share a common gene pool and can be reciprocally crossed resulting in fertile offspring without genetic isolation (Wang and $\mathrm{Li}$ 2011). The two species usually have a wide outcrossing rate of $2.4-37.4 \%$ in wild soybeans (Kiang et al.
1992; Fujita et al. 1997; Ohara and Shimamoto 2002; Kuroda et al. 2006), and extremely high values from 21.2 to $66.4 \%$ based on nuclear and chloroplast microsatellite variations (He et al. 2012). Furthermore, the most direct and convincing evidence that confirmed the natural occurrence of introgression between wild and cultivated soybeans was the natural F1 hybrids between maternal wild and paternal cultivated soybeans generated from original seed samples collected from wild soybean populations (Wang et al. 2010; Wang and Li 2011).

The first step for transgene escape is spontaneous hybridization between a transgenic crop and a compatible wild relative. Direct evidence for outcrossing from transgenic to wild soybeans has been reported in both Japan (Nakayama and Yamaguchi 2002; Mizuguti et al. 2009, 2010) and China (Chen et al. 2006; Liu et al. 2008, 2012, 2020). In these reports, different highest outcrossing rates were reported: $0.73 \%$ (Nakayama and Yamaguchi 2002), 0.19\% (Liu et al. 2020), and $0.097 \%$ (Mizuguti et al. 2010), due to different innate factors (reproductive compatibility, sympatry, and flowering synchrony), weather, and environmental conditions.

Besides the initial crop-weed hybridization, the likelihood of transgenes or other alleles spreading from crops to related wild populations depends on the fitness of the first and successive generations of hybrids (Hauser et al. 1998; Gueritaine et al. 2002; Jenczewski et al. 2003; Lu and Snow 2005; Kuroda et al. 2006; Guan et al. 2015; Kan et al. 2015). Fitness is reflected by vegetative and reproductive growth indicators and determines whether the hybrids can survive and establish (Warwick et al. 2009). Variation in fitness is expected across subsequent hybrid generations due to recombination between the genomes of wild and cultivated species (Kling 1996; Chèvre et al. 1997; Ammitzbøll 2005; Allainguillaume et al. 2006). The fitness of early hybrids relative to their parents determines transgene establishment in wild relatives (Jenczewski et al. 2003). Therefore, F1 hybrid viability/fertility should represent a bottleneck for transgene escape. For the alleles in one population to introgress to another, the initial hybrid generations must be viable and at least partially fertile (Chapman and Burke 2006).

The fitness of hybrids might vary widely, depending on the parental genotype, testing environment, and their interaction (Campbell and Waser 2001; Johnston 
et al. 2001; Johannessen et al. 2006; Whitney et al. 2006; Yang et al. 2011; Liu et al. 2016; Huang et al. 2019). Therefore, it is important to evaluate the fitness of hybrids of transgenic crops and wild relatives under different conditions. There is a dearth of previous research on the fitness of F1 hybrids obtained from wild and cultivated soybeans, including transgenic soybeans. Guan et al. (2015) measured the F1 hybrids of two wild soybeans and glyphosate-resistant soybean (AG5601) in a greenhouse, and found that two F1 hybrids had similar aboveground biomass, the same or $36 \%$ fewer pods, and the same or $54 \%$ fewer seeds per plant compared with their wild relatives. However, the 100-seed weight of two F1 hybrids was three times that of their respective wild relatives. Kan et al. (2015) reported on F1 hybrid performance obtained from four wild soybeans and glyphosate-resistant transgenic soybean. They found that four F1 hybrids performed differently compared with their wild relatives, e.g., differences were observed in pod number per plant, one of the four F1 hybrids produced $65 \%$ more, two produced $39 \%$ and $56 \%$ fewer, and the last one had a similar number of pods to its wild relative.

Although studies have shown that F1 hybrids between wild and cultivated soybeans exhibited performance that was lower, similar, or higher compared with that of their wild relatives for some traits, these results still do not fully reflect the potential ecological risks of cultivating GM soybeans in China because few populations of wild soybeans have been studied (Guan et al. 2015; Kan et al. 2015). In previous study, we collected 10 wild soybean populations from six provinces. The crossed seeds were obtained between these wild soybeans as maternal plants and transgenic glyphosate-resistant soybean as paternal plants (Hu et al. 2020). The average podding rates and the average filled seed number per pod of 10 wild soybean populations crossed with transgenic soybean ranged from $8.85-17.97 \%$, and from 0.20 to 0.48 , respectively. In the current study, the performance of F1 hybrids was measured in a net house without competition with weeds for $10 \mathrm{~F} 1$ hybrids as well as one F1 hybrid under competition with weeds. We aimed to predict the risk and consequences of gene flow from transgenic soybean to different wild soybeans and the potential risk without competition and under competition with weeds.

\section{Materials and methods}

The glyphosate-resistant (GR) soybeans (T14R 1251-70) were provided by the National Soybean Improvement Center of Nanjing Agricultural University. The GR soybean, contains one single-copy $c p 4$ epsps, was obtained by Agrobacterium-mediated cotransformation of the receptor soybean NJR44-1, which is an elite line bred by the National Soybean Improvement Center of Nanjing Agricultural University. The GR soybean withstands $3600 \mathrm{~g}$ a.i. $\mathrm{ha}^{-1} 41 \%$ glyphosate isopropylammonium AS (Roundup Ultra; Monsanto, St. Louis, MO, USA).Ten wild soybean populations were collected from six provinces, namely Heilongjiang, Jilin, Liaoning, Hebei, Henan, and Jiangsu, and the Inner Mongolia Autonomous Region during 2015-2016 (Table 1). Crossed seeds were

Table 1 Information of wild soybeans used in the experiments

\begin{tabular}{|c|c|c|}
\hline Collecting site & Population number & Latitude and longitude \\
\hline Harbin City, Heilongjiang Province & HLJHRB-1 & $\mathrm{N} 46^{\circ} 06^{\prime} 34^{\prime \prime}, \mathrm{E} 127^{\circ} 21^{\prime} 43^{\prime \prime}$ \\
\hline Harbin City, Heilongjiang Province & HLJHRB-2 & $\mathrm{N} 46^{\circ} 04^{\prime} 44^{\prime \prime}, \mathrm{E} 127^{\circ} 23^{\prime} 02^{\prime \prime}$ \\
\hline Baicheng City, Jilin Province & JLBC-1 & $\mathrm{N} 45^{\circ} 31^{\prime} 23^{\prime \prime}, \mathrm{E} 124^{\circ} 17^{\prime} 19^{\prime \prime}$ \\
\hline Baicheng City, Jilin Province & JLBC-2 & $\mathrm{N} 45^{\circ} 31^{\prime} 20^{\prime \prime}, \mathrm{E} 124^{\circ} 19^{\prime} 57^{\prime \prime}$ \\
\hline Tieling City, Liaoning Province & LNTL & $\mathrm{N} 42^{\circ} 17^{\prime} 28^{\prime \prime}, \mathrm{E} 123^{\circ} 51^{\prime} 47^{\prime \prime}$ \\
\hline Shenyang City, Liaoning Province & LNSY & $\mathrm{N} 41^{\circ} 32^{\prime} 41^{\prime \prime}, \mathrm{E} 123^{\circ} 27^{\prime} 29^{\prime \prime}$ \\
\hline Baotou City, Inner Mongolia Autonomous Region & IMBT & $\mathrm{N} 40^{\circ} 37^{\prime} 37^{\prime \prime}, \mathrm{E} 109^{\circ} 54^{\prime} 14^{\prime \prime}$ \\
\hline Handan City, Hebei Province & HBHD & $\mathrm{N} 36^{\circ} 38^{\prime} 59^{\prime \prime}, \mathrm{E} 114^{\circ} 36^{\prime} 35^{\prime \prime}$ \\
\hline Shangqiu City, Henan Province & HNSQ & $\mathrm{N} 34^{\circ} 22^{\prime} 21^{\prime \prime}, \mathrm{E} 115^{\circ} 40^{\prime} 18^{\prime \prime}$ \\
\hline Changzhou City, Jiangsu Province & JSCZ & $\mathrm{N} 31^{\circ} 37^{\prime} 13^{\prime \prime}, \mathrm{E} 119^{\circ} 29^{\prime} 53^{\prime \prime}$ \\
\hline
\end{tabular}


obtained by artificial hybridization of wild soybeans as the maternal plants crossed with transgenic soybean as the paternal plants from 2016 to 2017 (Hu et al. 2020). The crossed seeds were harvested from different mother plants, mixed, and then stored at $4{ }^{\circ} \mathrm{C}$ until further use. Experiments were conducted in a greenhouse and net house at the Pailou Experimental Farm $\left(118^{\circ} 37^{\prime} \mathrm{E}, 32^{\circ} 02^{\prime} \mathrm{N}\right)$, Nanjing Agricultural University, China, from 2017 to 2019.

\section{Seed sowing and emergence}

At the beginning of May of the next year (the second year for IMBT F1 and HNSQ F1) after crossed seeds were obtained by artificial hybridization, 20 filled seeds of each wild soybean population and transgenic soybean were selected from the 10 mother plants (two seeds from each plant). Then single filled seed of each wild soybean population and transgenic soybean were sown at $1 \mathrm{~cm}$ depth in individual pots $(7 \mathrm{~cm}$ diameter, $7.5 \mathrm{~cm}$ height) previously filled with a mixture of wasteland soil and organic cultivated soil (Green Island Horticultural Development Center, Zhenjiang, China) at a 1:1 (v/v) ratio. The filled crossed seeds were also selected and sown using the same method. Owing to limited filled crossed seeds obtained after artificial hybridization, six filled crossed seeds of JSCZ, HNSQ, and IMBT, 10 filled crossed seeds of LNTL, 15 filled crossed seeds of HLJHRB-2, JLBC-2, LNSY, and HBHD, 20 filled crossed seeds of HLJHRB-1, and 24 filled crossed seeds of JLBC-1 were randomly selected and each seed sown directly into individual plastic pots. The experiments were replicated five times. Number of wild soybeans and crossed seeds sown in the experiments are disclosed in detail in supplementary Table 1.

Pots were laid out in a completely randomized design in the same replicate in the greenhouse. Wild soybean seed coats were sturdy and durable under natural state, so the embryo-dorsal seed coats (on the opposite of hilum) of wild soybeans and crossed seeds were carefully nicked with a razor blade prior to sowing (seed coat was broken but the internal structure of the seeds was undamaged), to break the limit of imperviousness of the seed coat. Experimental pots were exposed to natural light and photoperiods, approximately 13 light/11 dark, and the temperature fluctuated from 22 to $28{ }^{\circ} \mathrm{C}$ during the experiment. The pots were watered as needed and hand weeded.
Emergence number of transgenic soybeans, wild soybeans, and crossed seeds was recorded when the cotyledon emerged from the soil and completely turned green approximately 2 weeks after sowing. Emergence rate $(\%)=($ emergence number $/$ number of seeds sown $) \times 100$. The length and width of cotyledons and true leaves were measured using vernier calipers (Shanghai Meinaite Industrial Co., Ltd, China) when the first trifoliolate leaf was not completely spread. The size of cotyledons and true leaves was calculated as the length $\mathrm{X}$ width of cotyledons + the lenght $X$ width of true leaves.

F1 hybrids confirmed by testing cp4-epsps gene

All emerging F1 seedlings were tested by PCR to confirm whether they contained the cp4-epsps gene. The DNA of each F1 seedling was extracted with a Plant Genomic DNA Kit [Tiangen Biotech (Beijing) Co., Ltd.], according to the manufacturer's instructions. A set of primer pairs for PCR analysis was designed using the sequence of the cp4-epsps gene included in the transgenic soybeans with Primer 6.0 Software (primer P1: 5'GGCACAAGGGATACAAACCC 3'; primer P2: $5^{\prime}$ ACCGCCGAACATGAAGGAC $3^{\prime}$ ).

Each PCR reaction involved a $20-\mu \mathrm{L}$ reaction solution containing $10 \mu \mathrm{L}$ of Premix Taq Version 2.0 plus dye [Treasure Biological Engineering (Dalian) Co., Ltd], $6 \mu \mathrm{L}$ of double distilled water, $1 \mu \mathrm{L}$ of forward primer $(10 \mu \mathrm{M}), 1 \mu \mathrm{L}$ of reverse primer $(10 \mu \mathrm{M})$, and $2 \mu \mathrm{L}$ of $20-30 \mathrm{ng} / \mu \mathrm{L}$ genomic DNA. PCR amplification was performed on a Whatman Biometra TGRADIENT Thermocycler at $95{ }^{\circ} \mathrm{C}$ for $5 \mathrm{~min}$ for the initial denaturation, 35 cycles of denaturation at $95{ }^{\circ} \mathrm{C}$ for $30 \mathrm{~s}$, annealing at $58{ }^{\circ} \mathrm{C}$ for $50 \mathrm{~s}$, elongation at $72{ }^{\circ} \mathrm{C}$ for $1 \mathrm{~min}$, and a final extension at $72{ }^{\circ} \mathrm{C}$ for $10 \mathrm{~min}$. Amplified DNA products were separated on $1 \%$ agarose gels at $120 \mathrm{~V}$ for $30 \mathrm{~min}$, stained with $10,000 \times$ SolarRed, and visualized under UV light. Wild and transgenic soybeans were used as negative and positive controls, respectively.

Seedling transplanting and variables measured

\section{Without weed competition}

At least 15 plants uniform in size of wild soybeans, transgenic soybeans (the transplanting number were the same with wild soybean in the same year), and 
Table 2 Number of wild soybeans and F1 hybrids transplanted in the experiments

\begin{tabular}{|c|c|c|c|c|c|c|c|}
\hline \multirow[t]{2}{*}{ Wild soybean } & \multicolumn{3}{|c|}{ Number } & \multirow[t]{2}{*}{ F1 Hybrid } & \multicolumn{3}{|c|}{ Number } \\
\hline & 2017 & 2018 & 2019 & & 2017 & 2018 & 2019 \\
\hline HLJHRB-1 & 30 & - & - & HLJHRB-1 F1 & 29 & - & - \\
\hline JLBC-1 & 30 & - & - & JLBC-1 F1 & 25 & - & - \\
\hline LNTL & 30 & - & - & LNTL F1 & 15 & - & - \\
\hline JSCZ & 30 & - & - & JSCZ F1 & 13 & - & - \\
\hline HLJHRB-2 & - & 20 & - & HLJHRB-2 F1 & - & 19 & - \\
\hline JLBC-2 & - & 20 & - & JLBC-2 F1 & - & 10 & - \\
\hline LNSY & - & 20 & - & LNSY F1 & - & 13 & - \\
\hline HBHD & - & 20 & - & HBHD F1 & - & 20 & - \\
\hline IMBT & - & - & 15 & IMBT F1 & - & - & 11 \\
\hline HNSQ & - & - & 15 & HNSQ F1 & - & - & 13 \\
\hline
\end{tabular}

10-29 F1 plants (Table 2) with the cp4-epsps gene were transplanted individually into pots with holes at the bottom ( 23 diameter $\mathrm{cm}, 25 \mathrm{~cm}$ height), containing the same growth media as described previously when the second trifoliolate leaf spread completely. On the third day after transplanting, a bamboo pole (2 diameter $\mathrm{cm}, 200 \mathrm{~cm}$ height) was inserted into the pots with wild soybeans and F1 seedlings for the plants to climb. Pots were watered and hand-weeded as needed. No chemicals were applied during the experiment. Seedlings were grown under natural conditions exposed to natural light (approximately 14-11 light) and temperature (approximately $15-35^{\circ} \mathrm{C}$ ) from the date of transplanting to harvesting (from the end of June to the end of November). Adjacent pots were separated by $60 \mathrm{~cm}$. Pots were laid out in a completely randomized design in the net house, and no sexually compatible Leguminosae species were present for a $100-\mathrm{m}$ radius around the experiment. The plant height was measured from the top of the plant to the cotyledonary node when the third trifoliolate leaf spread completely.

The other fitness components were measured as follows. Pollen viability was tested at the full flowering stage. Pollen was collected from nascent flowers at 7-8 am, and the in vitro pollen germination rate at 100 min was tested according to the method described by Liu and Liu (2018). At least 50 pollen grains from five flower buds on each of the one to three plants for wild soybean population, transgenic soybean and F1 plants were used as one replicate, and a total of nine replicates were assessed each time. Finally, the in vitro pollen germination rate was calculated as follows: (pollen germinated/pollen observed) $\times 100$. When pollen tube length was twice pollen grain length, it was considered to have germinated.

When $100 \%$ pods darkened (harvest maturity), each individual plant was separately harvested (cut from cotyledonary node). Each plant was sun dried to a constant weight and the aboveground dry biomass was weighed. The number of pods of each harvested plant was counted. All seeds were hand-peeled from the pods. Then, the number of filled seeds was counted for each plant. After being sun dried for 10 days in a greenhouse, 100 filled seeds were randomly counted from 10 plants and weighed for each wild soybean, transgenic soybean, and F1 hybrid.

\section{With weed competition}

On the same day of sowing wild soybeans and JLBC-1 F1 hybrids in the experiment without weed competition in 2017, $0.5 \mathrm{~g}$ of seeds each from Setaria viridis (L.) Beauv., Digitaria sanguinalis (L.) Scop., and Echinochloa colona (L.) Link., $0.25 \mathrm{~g}$ of seeds from Eleusine indica (L.) Gaertn., and $0.2 \mathrm{~g}$ of seeds from Amaranthus retroflexus L. were well mixed and then sown evenly on the surface of pots with holes in the bottom (52 diameter $\mathrm{cm}, 35 \mathrm{~cm}$ height). The pots contained the same media as those in the experiment without competition. These pots were watered and cultured in the net house.

We imposed interspecific competition by transplanting JLBC-1 F1 hybrids and its progenitors, JLBC-1 and transgenic soybeans, into recently established stands of weeds in 2017. Fifteen uniformly 


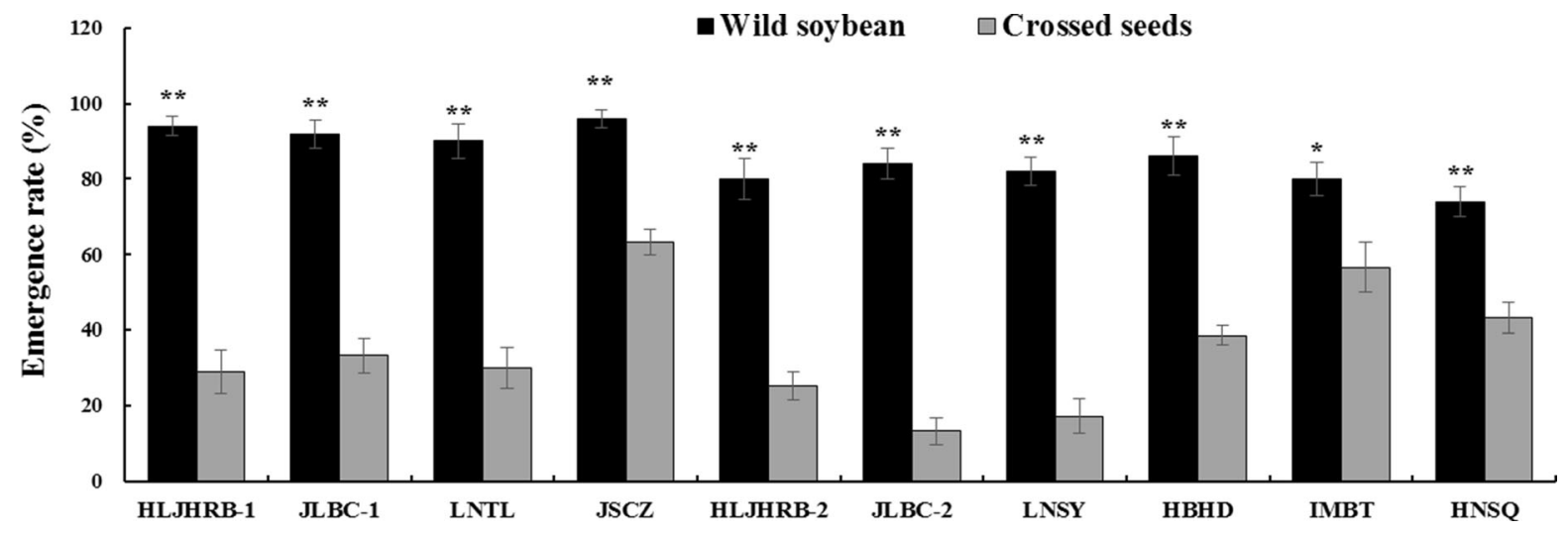

Fig. 1 Emergence rate of crossed seeds obtained from wild soybeans and transgenic soybean. Data were shown as the mean \pm SE. $*$ and $* *$ indicate significant differences $(P<0.05$

sized wild soybean of JLBC-1, transgenic soybean, and JLBC-1 F1 plants with the cp4-epsps gene were individually transplanted into the pots with weeds. The methods for measuring performance variables, including plant height, aboveground dry biomass, pod number per plant, and filled seed number per plant, were the same as those used in the experiment without weed competition.

\section{Statistical analysis}

Separation of the means of each measured variable was performed following the method described by Liu et al. (2016) using SPSS II 25.0 Software (IBM). Without weed competition, the means of every measured variable of wild soybeans and F1 hybrids were calculated. The average of each variable of wild soybeans was defined as ' 1 ', and the ratio of the variables between each F1 hybrid and its respective wild soybean was defined as the relative variable value. Composite fitness across the history of the whole cycle was the mean of the relative variable estimates for the entire cycle from vegetative to mature stages, including emergence rate, size of cotyledons and true leaves, plant height, aboveground dry biomass, pollen viability, pod number per plant, filled seeds per plant, and 100-seed weight.

The means of each variables and composite fitness for the F1 hybrids and the respective wild soybeans and $P<0.01$, respectively) between wild soybean and its crossed seeds with transgenic soybean separated using a t-test for independent samples

without weed competition were separated using a t-test for independent samples.

With weed competition, the performance of all variables among F1 hybrids, wild soybeans, and transgenic soybean were separated using Duncan's multiple range test. The composite fitness of JLBC-1, its F1 hybrid and transgenic soybean was the mean of the relative variable estimates for plant height, aboveground dry biomass, pod number per plant, filled seeds per plant, and 100-seed weight without weed competition compared with those under weed competition. The difference in composite fitness of JLBC-1, its hybrids and transgenic soybean without and with weed competition were separated using a $\mathrm{t}$-test for independent samples.

\section{Results}

Emergence rate of crossed seeds

Wild soybeans displayed an emergence rate of 74.00-96.00\%. The emergence rate of crossed seeds was $23.33-70.67 \%$ less than that of their respective wild soybeans $(P<0.01$ for nine F1 hybrids except for IMBT, it's was $P<0.05$ ) (Fig. 1).

\section{Glyphosate-resistant gene transmission}

The glyphosate-resistant gene PCR amplification tests showed that the cp4-epsps (313 bp) fragments from the transgenic soybeans were highly conserved in the 


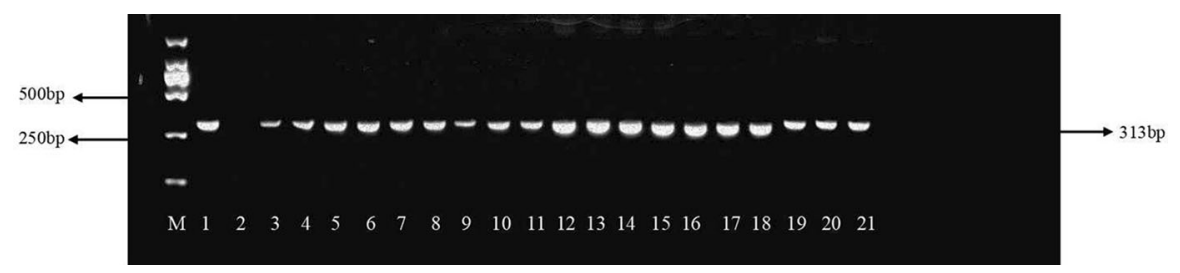

Fig. 2 PCR amplification of cp4psps gene fragment from the F1 hybrids between wild soybean HLJHRB-2 and transgenic glyphosate-tolerant soybean. M: marker DL2000; 1: Glyphosate

F1 hybrids (Fig. 2, taking F1 hybrids of HLJHRB-2 as an example).

\section{Without weed competition}

All wild soybean, transgenic soybean, and F1 hybrid plants grew and flowered vigorously, and no plants died from transplanting to harvest. The morphology of nine F1 hybrids was twinning, and black pod, small darker seeds traits from wild soybeans. Seeds size and color of IMBT F1 hybrid were intermediate between those of the parents. We compared the performances of F1 hybrids and their wild soybeans in Table 3. The performance of transgenic soybean in 3 years is shown in Supplementary Table 2.

\section{Performance in the vegetative stage}

Most F1 hybrids had cotyledons that were significantly smaller in both length and width as were the true leaves $(P<0.01)$. However, LNTL F1 hybrids exhibited cotyledons and true leaves of similar sizes. HNSQ F1 hybrids had similar cotyledons size and true leaves length. HLJHRB-2 F1 hybrids had cotyledons of similar length. Nine of the $10 \mathrm{~F} 1$ hybrids were significant shorter at $71.55-15.39 \%(P<0.01)$ the height of their wild soybeans, except for HNSQ F1 hybrids, which were $17.88 \mathrm{~cm}$ tall, similar to HNSQ. Seven of the $10 \mathrm{~F} 1$ hybrids had significantly lower aboveground dry biomass (61.34-18.44\%) than their respective wild parents $(P<0.01)$. HNSQ F1 and HLJHRB-1 F1 hybrids were 12.69 and $11.43 \%$ $(P<0.05)$ lower. IMBT F1 hybrids were an exception at $90.39 \%$ higher than its wild parent (Table 3 ). resistant transgenic soybean; 2: Wild soybean HLJHRB-2; 3-21: F1 hybrids of HLJHRB-2

\section{Performance on reproductive stage}

The pollen germination rates of wild soybeans ranged from $71.13 \%$ to $95.93 \%$ in the in vitro experiments at $100 \mathrm{~min}$, while the pollen germination rates of F1 hybrids were $49.57-82.17 \%$, which were significantly lower than those of their wild parents $(P<0.01)$. F1 hybrids of HLJHRB-1, JLBC-1, LNTL, HLJHRB-2, and HNSQ produced $15.88-77.56 \%$ fewer pods per plant than their wild progenitors $(P<0.01)$. JSCZ F1, JLBC-2 F1, LNSY F1, HBHD F1, and IMBT F1 produced 188.82-397.55 pods per plant, which was similar to the number produced by their wild parents.

All 10 F1 hybrids produced significantly fewer filled seeds per plant than their wild parents $(P<0.01)$ at 169.80-757.80. HNSQ F1, IMBT F1, JLBC-2 F1, and JSCZ F1 hybrids exhibited better performance, which difference with wild parents were 22.92, 36.23, 39.90 , and $46.98 \%$, respectively. The filled seed number of HLJHRB-1 F1, HLJHRB-2 F1, and LNSY F1 hybrids was approximately $50 \%$ of that of their wild parents. JLBC-1 F1 and LNTL F1 hybrids produced 77.08 and $91.17 \%$ fewer seeds than their wild parents.

Compared with their respective wild parents, LNTL F1, HLJHRB-2 and JLBC-2 F1 hybrids had no significant differences in 100 -seed weight. In the other six F1 hybrids, 100-seed weight was significantly lower $(7.52-13.87 \%)$ than that of their wild progenitors $(P<0.01$ or 0.05$)$. However, IMBT F1 hybrids had a large 100-seed weight (5.52 g), which was $256.13 \%$ greater than that of its wild parent. Besides larger seeds, the seed coat color of IMBT F1 hybrids turned to the color of transgenic soybean. Pictures of the seeds are shown in Supplementary Fig. 1. 


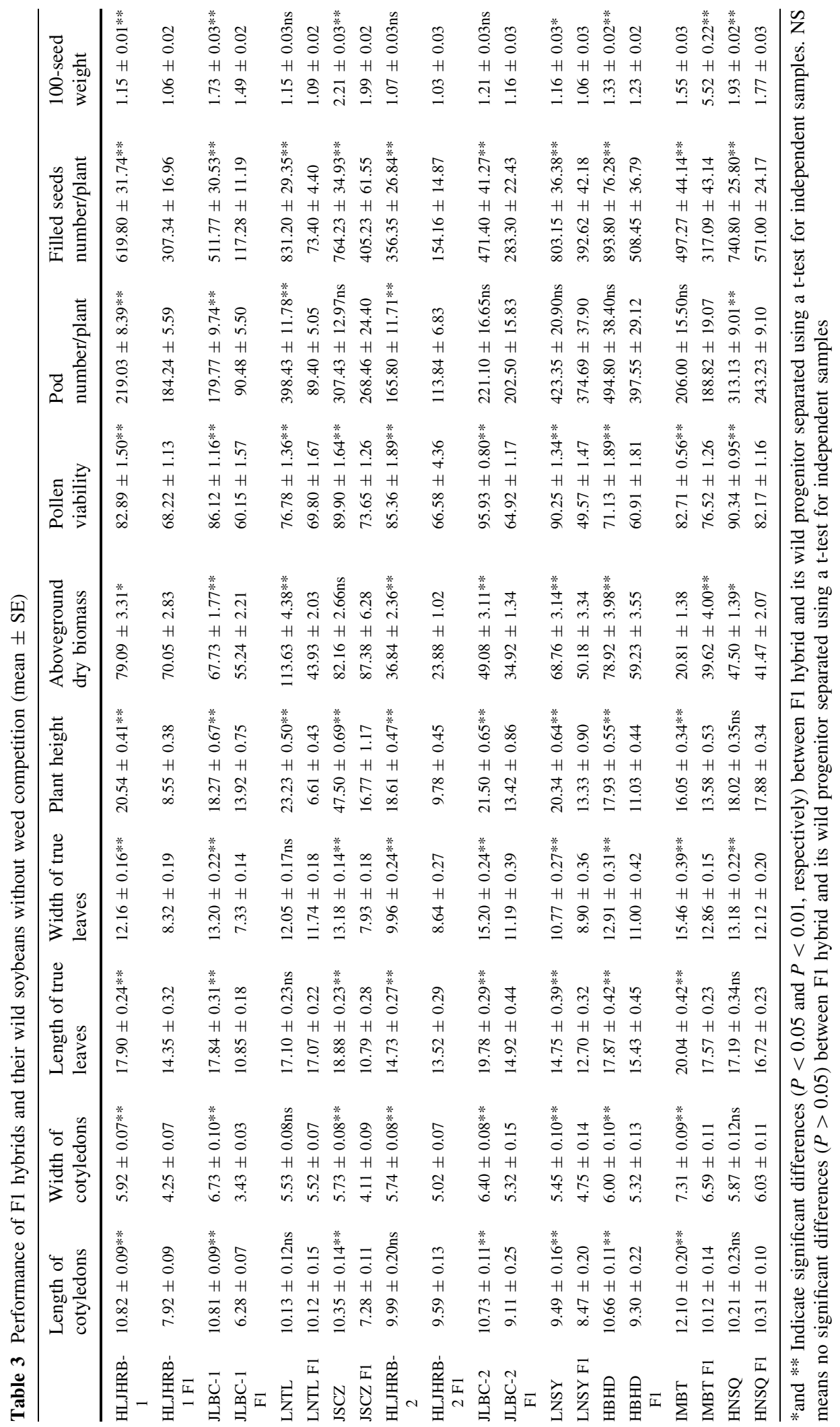




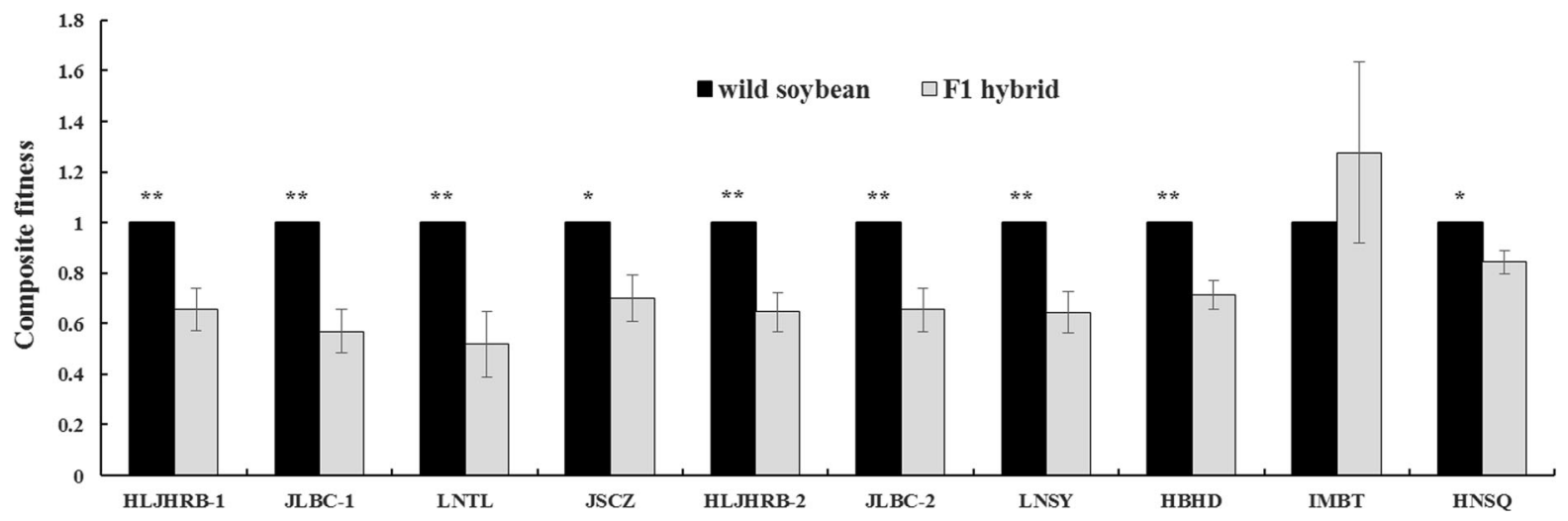

Fig. 3 Composite fitness of F1 hybrids and their wild soybeans without weed competition. To estimate composite fitness, the variables of wild soybean were defined as ' 1 '. Data were shown as the mean $\pm \mathrm{SE}(\mathrm{n}=8)$. * and $* *$ indicate significant

\section{Composite fitness}

Nine of the $10 \mathrm{~F} 1$ hybrids remained less fit than their wild progenitors, with composite fitness ranging from 0.52 to 0.84 . One exceptional F1 hybrid was IMBT F1 with 1.28 composite fitness, which was similar to that of its wild progenitor $(P=0.4590)$ (Fig. 3). It had a similar number of pods and an increased aboveground dry biomass and 100-seed weight compared with its wild progenitor.

With weed competition

Weeds grew vigorously and similarly in each pot in the whole experiment. After being harvested, weeds occurred in JLBC-1 F1 hybrid and its progenitor wild soybean and transgenic soybean at 95.62, 98.16, and $103.27 \mathrm{~g}$, but there was no significant difference in aboveground dry biomass. This implied that the interference of weeds on JLBC-1 F1 hybrid and its progenitors was similar.

Five plants of JLBC-1 F1 hybrids died at the earlier third trifoliolate leaf stage after transplanting. Two plants of JLBC-1 died at the later third trifoliolate leaf stage. JLBC-1 F1 hybrids performed much weaker compared with its wild and cultivated parents. The plant height, aboveground dry biomass, pod number per plant, filled seeds number per plant, and 100-seed weight were lower by 29.70, 57.19, 53.22, 64.90, and $17.72 \%$, respectively, than its wild progenitor JLBC-1 $(P<0.05)$. The plant height, aboveground dry biomass, and 100 -seed weight were lower by 59.00 , differences ( $P<0.05$ and $P<0.01$, respectively) between F1 hybrid and its wild progenitor separated using a t-test for independent samples

83.55, and $90.97 \%$, respectively, than its paternal parent transgenic soybean $(P<0.05)$. Meanwhile, JLBC-1 F1 produced $65.10 \%$ more pods per plant $(P<0.05)$ and $24.79 \%$ more filled seeds per plant than its paternal parent transgenic soybean (Table 4).

Comparing performance with and without weed competition

Weed competition impacted the performance of JLBC-1 F1 hybrids and their wild and cultivated progenitor. JLBC-1 F1 hybrids decreased by 17.53 , $64.96,48.50$ and $12.75 \%$ in plant height, pod number per plant, filled seeds per plant, and 100-seed weight, respectively, which did not have much more differences with those of its maternal wild soybean and paternal transgenic soybean. However, aboveground dry biomass of JLBC-1 F1 hybrids decreased by $70.13 \%$, while its maternal and paternal plants decreased by $43.10 \%$ and $22.54 \%$ (Table 5). Finally, the composite fitness of JLBC-1, its F1 generation and transgenic soybean was $0.62,0.57$, and 0.58 compared with those without weed competition (Fig. 4).

\section{Discussion}

\section{Emergence rate}

The growth cycle of annual plants begins with the germination of seeds. Plant species with annual life cycles completely depend on seed germination 
Table 4 Performance of transgenic soybean, wild soybean JLBC-1 and their F1 hybrid under weed competition (Mean \pm SE)

\begin{tabular}{lcrr}
\hline Trait & Transgenic soybean & JLBC-1 & JLBC-1 F1 \\
\hline Plant height $(\mathrm{cm})$ & $28.00 \pm 1.20 \mathrm{a}$ & $16.33 \pm 0.69 \mathrm{~b}$ & $11.48 \pm 0.59 \mathrm{c}$ \\
Aboveground dry biomass $(\mathrm{g})$ & $100.33 \pm 3.40 \mathrm{a}$ & $38.54 \pm 2.79 \mathrm{~b}$ & $16.50 \pm 1.74 \mathrm{c}$ \\
Pod number/plant & $19.2 \pm 1.94 \mathrm{c}$ & $67.77 \pm 5.30 \mathrm{a}$ & $31.70 \pm 3.64 \mathrm{~b}$ \\
Filled seed number/plant & $48.4 \pm 5.16 \mathrm{~b}$ & $172.08 \pm 18.40 \mathrm{a}$ & $60.40 \pm 6.88 \mathrm{~b}$ \\
100-seed weight $(\mathrm{g})$ & $14.39 \pm 0.12 \mathrm{a}$ & $1.58 \pm 0.04 \mathrm{~b}$ & $1.30 \pm 0.04 \mathrm{c}$ \\
\hline
\end{tabular}

Different letters in the same row indicate significant differences among transgenic soybean, JLBC-1 and JLBC-1 F1 using Duncan's multiple range test, $P<0.05$

Table 5 The decreased percentage (\%) of JLBC-1 F1 hybrid and its progenitors performance under weed competition compared with those without weed competition

\begin{tabular}{llll}
\hline Traits & Transgenic soybean & JLBC-1 & JLBC-1 F1 \\
\hline Plant height $(\mathrm{cm})$ & $10.00^{*}$ & 10.62 & 17.53 \\
Aboveground dry biomass $(\mathrm{g})$ & $22.54^{*}$ & $43.10^{* *}$ & $70.13^{* *}$ \\
Pod number/plant & $77.09^{* *}$ & $62.30^{* *}$ & $64.96^{* *}$ \\
Filled seed number/plant & $76.99^{* *}$ & $66.38^{* *}$ & $48.50^{* *}$ \\
100 -seed weight $(\mathrm{g})$ & $21.28^{* *}$ & $8.67 * *$ & $12.75^{* *}$ \\
\hline
\end{tabular}

$*$ and ** indicate significant difference of F1 hybrid, or its wild progenitor or transgenic soybean under weed competition compared with those without weed competition separated using a t-test for independent samples $(P<0.05$ and $P<0.01)$

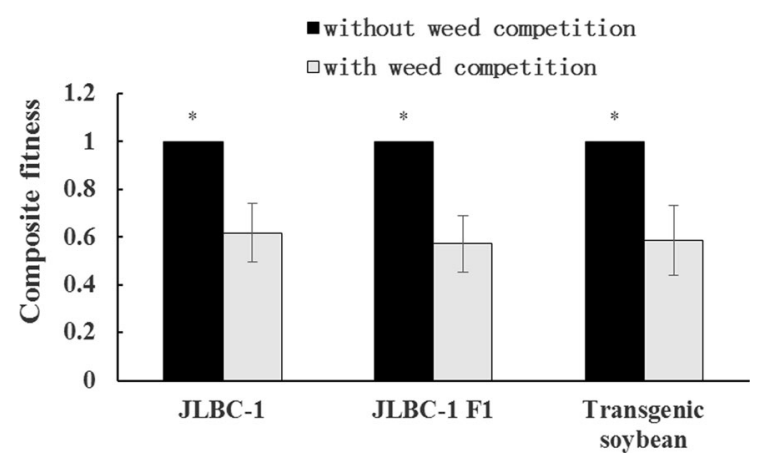

Fig. 4 Composite fitness of JLBC-1 F1 hybrid and its parents with weed competition compared with those without weed competition. To estimate composite fitness, the variables without weed competition were defined as ' 1 '. Data were shown as the mean $\pm \mathrm{SE}(\mathrm{n}=5$, Plant height, Aboveground dry biomass, Pod number/plant, Filled seed number/plant, and 100 -seed weight). $*$ indicate significant differences $(P<0.05)$ between composite fitness with weed competition compared with those without weed competition of F1 hybrid, its wild progenitor or transgenic soybean separated using a t-test for independent samples
(Calado et al. 2011). In our study, all crossed seeds obtained from maternal wild soybeans and transgenic soybeans emerged at $13.33-63.33 \%$, indicating that these crossed seeds were viable. However, crossed seeds emerged at a lower rate than those of their wild progenitors. A lower emergence rate may be a factor restricting $\mathrm{F} 1$ hybrids from establishing populations. The reason may be lower seed viability rather than seed coat impermeability. Seed and embryo viability are associated. Although cultivated soybeans and wild soybeans carry similar genomes $(\mathrm{GG}, 2 \mathrm{n}=40)$ (Singh and Hymowitz 1985, 1988), the meiotic aberrations, heteromorphic chromosome pairing for chromosomes 6 and 11, were observed in G. $\max \times$ G. soja F1 hybrids (Singh and Hymowitz 1988). Moreover, wild soybean accessions were separated into two types on the basis of chromosome structure; $19 \%$ had normal chromosome structure, while $81 \%$ had chromosome interchange (Palmer et al. 1987). Chromosome interchanges resulted in bridges and multivalent formation 
during meiosis that reduce pollen and seed fertility in hybrids (Palmer et al. 2000). Therefore, the variable crossed seed viability should be due to cryptic structural differences between wild and cultivated soybeans as well as genotype differences in wild soybeans.

Hard seededness of wild soybeans is an adaptive character to survive for long periods in adverse wild environments and germinate at a favorable time. This characteristic in cultivated soybeans has been greatly reduced through artificial selection (Zhou et al. 2010; $\mathrm{Vu}$ et al. 2014). We did not evaluate the water permeability of crossed seeds because we obtained limited seeds after artificial hybridization. The crossed seeds could lose this favorable characteristic due to the influence of the transgenic soybean seed coat allele, which is responsible for the reduction in F1 hybrid fitness. The increased permeability in seeds obtained from wild soybeans and transgenic soybeans as well as offspring of F1 hybrids will not protect seeds against deterioration, and maintain viability in natural environments. From this point, F1 hybrids may exhibit lower fitness. However, fitness of F1 plants may be potentiality increased in further generation either by selfing or backcrossing to wild parents.

Without competition

\section{Plant height}

Wild soybeans are herbaceous annual plants and the seeds fall from the parental plants, which die at the end of the growing season, and the seeds grow out from the soil surface either in growing or already established vegetation. This often results in severe competition for light with surrounding plants at early stages of their growth. Under this circumstance, taller plants at early stages of their growth could contribute to this competitiveness during the initial phases of plant establishment and growth (den Dubbelden and Verburg 1996). Taller plants are more competitive than shorter ones due to better light interception, which is directly associated with the photosynthetic activity of the plant (Cudney et al. 1991; Caton et al. 1999; Cousens et al. 2003a, b; West et al. 2010; Denison et al. 2010).

In the present study, we measured plant height at the third trifoliolate leaf stage, and found that nine of the $10 \mathrm{~F} 1$ hybrids were significant shorter $(P<0.05)$ than wild soybeans by $15.39-71.55 \%$, except for
HNSQ F1, which was similar to its wild progenitor. The results implied that most $\mathrm{F} 1$ hybrids had a disadvantage in plant height compared with maternal wild soybeans at the seedling stage. The results on plant height of F1 hybrids were similar to that of the previous study (Kan et al. 2015). Even though, the plant height of F1 hybrids may change in different environment. Therefore, further research should be conducted in different environment.

\section{Aboveground dry biomass}

Variation in the total biomass of annual plants at the end of the growing season reflects differences in resource capture and biomass production rate (Dovrat et al. 2019). High aboveground dry biomass implied more competitiveness. Nine of the $10 \mathrm{~F} 1$ hybrids had significantly lower aboveground dry biomass than their respective wild parents $(P<0.01)$. This result implied that these nine F1 hybrids were weaker in resource capture and biomass production rate compared with their wild progenitors. However, IMBT F1 hybrids exhibited $90.39 \%$ higher aboveground dry biomass than its wild parent. In the current research, the difference in aboveground dry biomass between F1 hybrids, and their wild soybean relatives could be determined by the genotypes of wild soybeans rather than other variation and interactions in environmental or experimental condition. Wild soybeans harbor a high level of genetic variation, and most of the variation was found within the populations and groups, but significant genetic differentiation was also detected among different eco-geographical groups (Dong et al. 2001; Wen et al. 2009; Wang et al. 2014, 2017). Considering the higher level of genetic diversity retained in wild soybeans, this may complicate the consequences of gene flow from transgenic to wild soybeans.

\section{Reproductive ability}

The reproductive ability of hybrids is one of the most important traits for assessing fitness (Liu et al. 2016). In the present study, reproductive variables of $10 \mathrm{~F} 1$ hybrids, including pollen viability and filled seed number per plant, were significantly lower than those of their wild progenitors. Therefore, F1 hybrids may pose less potential ecological risk. Despite all of this, F1 hybrids produced 73-571 filled seeds per plant, and 
these seeds could, in the next year, germinate seedlings carrying resistant genes, which could survive and produce progenies, especially under glyphosate selection. Moreover, F1 hybrids could backcross with wild progenitors. Thus, the transgenes or other cultivated soybean genes that confer a selective advantage may introgress into wild soybeans.

\section{0-seed weight}

The Chinese wild soybean (Glycine soja) has three clear genetic categories: small-seeded (100-seed weight under $2.0 \mathrm{~g}$ ), medium-seeded (100-seed weight of 2.01-2.5 g), and large-seeded (100-seed weight of 2.51-3.0 g). The semi-wild soybean (Glycine gracilis) usually had more than $3.0 \mathrm{~g} 100$-seed weight (Wang et al. 2012, 2014). In the current research, six typical small-seed types of wild soybeans with 100 -seed weight $<1.5$, three small-seed types, JLBC-1, IMBT, and HNSQ (1.6-2.0 g), and one middling seed type JSCZ were used to study the performance of F1 hybrids. The results demonstrated that nine of the $10 \mathrm{~F} 1$ hybrids had lower 100-seed weight compared with their wild progenitors. These results differed from those of Guan et al. (2015) and Kan et al. (2015). Two F1 hybrids were approximately $200 \%$ more than wild progenitors in the former, and four F1 hybrids were 61-292\% more than their wild progenitors in the latter. However, IMBT F1 hybrids had $5.52 \mathrm{~g}$ per 100-seed weight, which was 3.56 times that of maternal wild soybean. According to the genetic categories criterion (Wang et al. 2012, 2014), IMBT F1 hybrids should belong to the semi-wild type (G. gracilis), which originated from reciprocal hybridization between wild and cultivated soybeans (Wang et al. 2010).

Wang and Li (2011) provided the most direct and convincing evidence that confirmed the natural occurrence of introgression between wild and cultivated soybeans and the hybridization origin of G. gracilis. Natural wild-cytoplasmic semi-wild type hybrids (F1) were found between the maternal wild soybeans (collected from Keyouqianqi, Inner Mongolian) and paternal cultivated soybeans. These novel plants produced more seeds with a mean of $4.6 \mathrm{~g}$ of 100 -seed weight (4.6 times that of wild soybeans). Beside the 100 -seed weight, these hybrid plants distinctly differed from their maternal wild soybean populations by having thicker mean diameter for basal stem, higher yield per plant, and aboveground dry mass weight of $18.3 \mathrm{~g}$ (5.1 times that of maternal wild soybeans). Similarly, IMBT F1 hybrids had 1.90 times the aboveground dry biomass weight of maternal wild soybeans. The results indicate that gene flow from transgenic soybeans to certain wild soybeans may generate herbicide resistant G. gracilis. Therefore, the risk of gene flow from transgenic soybeans to different wild soybean populations must be evaluated before commercial release.

\section{Composite fitness}

The crossed seed emergence rate, plant height, aboveground dry biomass, fecundity (filled seeds number per plant), and 100-seed weight of F1 hybrids showed greater variability among wild soybeans and transgenic soybeans under benign conditions. The composite fitness ranged from 0.52 to 0.84 , with one exception reaching 1.28 across genetic backgrounds. Mercer et al. (2007) found that the hybrid fitness of wild Helianthus annuus from different places and cultivated $H$. annuus demonstrated the variable responses to stressful environments. The initial phases of introgression could vary radically in different populations growing under diverse conditions (Mercer et al. 2007). The current results suggest that the introgression from transgenic soybeans into different genotypes of wild soybeans may have different fitness consequences, especially under different condition.

With weed competition

Weeds may be one of the major constraints to growth of F1 hybrids of wild soybeans and transgenic soybeans in agricultural systems or other system by competing for nutrients, sunlight, space, and water (Renton and Chauhan 2017; Song et al. 2017). Owing to limited crossed seeds, only JLBC-1 F1 hybrids and their progenitors were studied in the presence of weed competition. As expected, the performance of JLBC-1 $\mathrm{F} 1$ hybrids and their wild and cultivated progenitors decreased in plant height (F1 hybrid and JLBC-1 had no significant difference), aboveground dry biomass, pod number per plant, filled seeds per plant, and 100 -seed weight as well as composite fitness with weed competition $(P<0.05)$. Nonetheless, JLBC-1 F1 hybrids produced 60 filled seeds per plant. From a mechanistic standpoint, the extent of gene 
introgression depends on the interactions between recombination and selection (Jenczewski et al. 2003). In herbicide-resistant transgenic soybean fields, weeds will be killed and F1 hybrids carrying resistant genes will survive under herbicide selection. Therefore, once the initial gene flow occurred through pollen from transgenic to wild soybeans, the F1 hybrids could survive and complete their life cycle in the face of either weed competition or herbicide selection.

\section{Conclusion}

Without weed competition, compared with their respective wild soybean relatives, crossed seeds obtained from wild soybeans as maternal plants and glyphosate-resistant transgenic soybean as paternal plants emerged at low rates and the composite fitness of nine F1 hybrids was significantly lower except for IMBT F1 hybrid that had similar fitness to its wild progenitor. With weed competition, JLBC-1 F1 hybrids displayed lower fitness than their wild soybean relative. However, all F1 hybrids produced approximately 70-500 filled seeds/plant in absence of weed competition. Moreover, two thirds of JLBC-1 F1 hybrids survived, and produced 60 filled seeds/plant under weed competition. The results implied that $\mathrm{F} 1$ hybrids may establish in nature environment.

Acknowledgements This study was funded by grants from the National Special Transgenic Project of China (2016ZX08012005) and the National Natural Science Foundation of China (32071656). No competing interests exist in the presentation of information generated from this study. Xiao-ling Song and Ze-Wen Sheng performed the statistical analysis and drafted the manuscript. Jin-Yue Liu, Ze-Wen Sheng, Yu-Qi Hu, Qi Liu, participated in the data collection. Xiao-ling Song, Sheng Qiang and Biao Liu designed the research. All authors have read and approved the final manuscript.

Open Access This article is licensed under a Creative Commons Attribution 4.0 International License, which permits use, sharing, adaptation, distribution and reproduction in any medium or format, as long as you give appropriate credit to the original author(s) and the source, provide a link to the Creative Commons licence, and indicate if changes were made. The images or other third party material in this article are included in the article's Creative Commons licence, unless indicated otherwise in a credit line to the material. If material is not included in the article's Creative Commons licence and your intended use is not permitted by statutory regulation or exceeds the permitted use, you will need to obtain permission directly from the copyright holder. To view a copy of this licence, visit http://creativecommons.org/licenses/by/4.0/.

\section{References}

James C (2019) Preview: Global status of commercialized biotech/GM Crops: 2018. ISAAA Briefs, 54

James C (2018) Preview: Global status of commercialized biotech/GM Crops: 2017. ISAAA Briefs, 53

Akpertey A, Belaffif M, Graef GL, Mian MAR, Shannon JG, Cregan PB, Hudson ME, Diers BW, Nelson RL (2014) Effects of selective genetic introgression from wild soybean to soybean. Crop Sci 54:2683-2695. https://doi.org/ 10.2135/cropsci2014.03.0189

Allainguillaume J, Alexander M, Bullock JM, Saunders M, Allender CJ, King G, Ford CS, Wilkinson MJ (2006) Fitness of hybrids between rapeseed (Brassica napus) and wild Brassica rapa in natural habitats. Mol Ecol 15:1175-1184. https://doi.org/10.1111/j.1365-294X.2006. 02856.x

Ammitzbøll H, Mikkelsen TN, Jørgensen RB (2005) Transgene expression and fitness of hybrids between GM oilseed rape and Brassica rapa. Environ Biosaf Res 4:3-12. https://doi. org/10.1051/ebr:2005010

Calado JMG, Basch G, Carvalho M (2011) Weed emergence in autumn under temperate conditions. Planta Daninha 29:343-349. https://doi.org/10.1590/S010083582011000200012

Campbell DR, Waser NM (2001) Genotype-by-environment interaction and the fitness of plant hybrids in the wild. Evolution 55:669-676. https://doi.org/10.1111/j.00143820.2001.tb00802.x

Caton BP, Foin TC, Hill JE (1999) A plant growth model for integrated weed management in direct-seeded rice. III. Interspecific competition for light. Field Crops Research 63:47-61. https://doi.org/10.1016/S0378-4290(99)00013-1

Chapman MA, Burke JM (2006) Letting the gene out of the bottle: the population genetics of genetically modified crops. New Phytol 170:429-443. https://doi.org/10.1111/j. 1469-8137.2006.01710.x

Chen X, Yan JG, Gao B, Sb P (2006) Gene flow from transgenic roundup-ready soybean to wild soybean. Agricultural Science and Technology 7(1):8-13

Chèvre AM, Eber F, Baranger A, Renard M (1997) Gene flow from transgenic crops. Nature 389:924. https://doi.org/10. 1038/40054

Cousens RD, Barnett AG, Barry GC (2003a) Dynamics of competition between wheat and oat: I. Effects of changing the timing of phenological events. Agron J 95:1295-1304. https://doi.org/10.2134/agronj2003.1295

Cousens RD, Rebetzke GJ, Barnett AG (2003b) Dynamics of Competition between Wheat and Oat: II. Effects of Dwarfing Genes Agronomy Journal 95:1305-1313. https:// doi.org/10.2134/agronj2003.1305

Cudney DW, Jordan LS, Hall AE (1991) Effect of wild oat (Avena fatua) infestations on light interception and growth rate of wheat (Triticum aestivum). Weed Sci 39:175-179. https://doi.org/10.1017/S0043174500071435 
den Dubbelden KC, Verburg RW (1996) Inherent allocation patterns and potential growth rates of herbaceous climbing plants. Plant Soil 184(2):341-347. https://doi.org/10.1007/ BF00010463

Denison RF, Fedders JM, Harter BL (2010) Individual fitness versus whole-crop photosynthesis:solar tracking tradeoffs in alfalfa. Evol Appl 3:466-472. https://doi.org/10.1111/j. 1752-4571.2010.00148.x

Dong YS, Zhuang BC, Zhao LM, Sun H, He MY (2001) The genetic diversity of annual wild soybeans grown in China. Theoretical and Applied Genetics 103(1):98-103. https:// doi.org/10.1007/s001220000522

Dovrat G, Meron E, Shachak M, Golodets C, Osem Y (2019) Plant size is related to biomass partitioning and stress resistance in water-limited annual plant communities. J Arid Environ 165:1-9. https://doi.org/10.1016/j.jaridenv. 2019.04.006

Fujita R, Ohara M, Okazaki K, Shimamoto Y (1997) The extent of natural cross-pollination in wild soybean (Glycine soja). The Journal of Heredity 88:124-128. https://doi.org/10. 1093/oxfordjournals.jhered.a023070

Goto H, Mcpherson MA, Comstock BA, Stojsin D, Ohsawa R (2017) Likelihood assessment for gene flow of transgenes from imported genetically modified soybean (Glycine max (L.) Merr.) to wild soybean (Glycine soja Seib. et Zucc.) in Japan as a component of environmental risk assessment. Breed Sci 67:348-356. https://doi.org/10.1270/jsbbs. 16134

Guan ZJ, Zhang PF, Wei W, Mi XC, Kang DM, Liu B (2015) Performance of hybrid progeny formed between genetically modified herbicide-tolerant soybean and its wild ancestor. AoB Plants. https://doi.org/10.1093/aobpla/ plv121

Gueritaine G, Sester M, Eber F, Chevre AM, Darmency H (2002) Fitness of backcross six of hybrids between transgenic oilseed rape (Brassica napus) and wild radish (Raphanus raphanistrum). Mol Ecol 11:1419-1426. https://doi.org/10.1046/j.1365-294X.2002.01540.x

Hauser TP, Jorgensen RB, Ostergard H (1998) Fitness of backcross and F2 hybrids between weedy Brassica rapa and oilseed rape (B. napus). Heredity 81:436-443. https:// doi.org/10.1046/j.1365-2540.1998.00425.x

He S, Wang Y, Volis S, Li D, Yi T (2012) Genetic diversity and population structure: implications for conservation of wild soybean (Glycine soja Sieb et Zucc) based on nuclear and chloroplast microsatellite variation. Int $\mathrm{J}$ Mol Sci 13:12608-12628. https://doi.org/10.3390/ijms131012608

Hu YQ, Sheng ZW, Liu JY, Qiang S, Song XL, Liu B (2020) Sexual compatibility of transgenic soybean and different wild soybean populations. J Integr Agri 19: 2-14. https:// doi.org/10.1016/S2095-3119(20)63385-8

Huang Y, Wang YY, Qiang S, Song XL, Dai WM (2019) Fitness of $\mathrm{F} 1$ hybrids between stacked transgenic rice T1c-19 with cry $1 C * /$ bar genes and weedy rice. Journal of Integrative Agriculture 18:2793-2805. https://doi.org/10.1016/S20953119(19)62662-6

Jenczewski E, Ronfort J, Chevre AM (2003) Crop-to-wild gene flow, introgression and possible fitness effects of transgenes. Environ Biosaf Res 2:9-24. https://doi.org/10.1051/ ebr:2003001
Johannessen MM, Andersen BA, Jorgensen RB (2006) Competition affects gene flow from oilseed rape (+) to Brassica rapa (ô). Heredity 96:360-367. https://doi.org/10.1038/sj. hdy. 6800796

Johnston JA, Grise DJ, Donovan LA, Arnold ML (2001) Environment-dependent performance and fitness of Iris brevicaulis, I. fulva (Iridaceae), and hybrids. Am J Bot 88:933-938. https://doi.org/10.2307/2657046

Kan GZ, Tong ZF, Hu ZB, Ma DY, Zhang GZ, Yu DY (2015) Fitness of hybrids between wild soybean (Glycine soja) and the glyphosate-resistant transgenic soybean (Glycine max). Soybean Science 34(2):177-184. https://doi.org/10.1093/ aobpla/plv121

Kiang YT, Chiang YC, Kaizuma N (1992) Genetic diversity in natural populations of wild soybean in Iwate prefecture, Japan. J Hered 83:325-329. https://doi.org/10.1093/ oxfordjournals.jhered.a111225

Kling J (1996) Agricultural ecology-Could transgenic supercrops one day breed superweeds? Science 274:180-181. https://doi.org/10.1126/science.274.5285.180

Kuroda Y, Kaga A, Tomooka N, Vaughan DA (2006) Population genetic structure of Japanese wild soybean (Glycine soja) based on microsatellite variation. Mol Ecol 15:959-974. https://doi.org/10.1111/j.1365-294X.2006. 02854.x

Li XH, Wang KJ, Jia JZ (2009) Genetic diversity and differentiation of Chinese wild soybean germplasm (G. soja Sieb. \& Zucc.) in geographical scale revealed by SSR markers. Plant Breeding 128(6):658-664. https://doi.org/ 10.1111/j.1439-0523.2009.01625.x

Li YH, Li W, Zhang C, Yang L, Chang RZ, Gaut BS, Qiu LJ (2010) Genetic diversity in domesticated soybean (Glycine max) and its wild progenitor (Glycine soja) for simple sequence repeat and single-nucleotide polymorphism loci. New Phytol 188:242-253. https://doi.org/10.1111/j.14698137.2010.03344.x

Liu B, Xue K, Liu LP, Shen WJ, Guo H (2020) Research on the gene flow from transgenic EPSPS +PAT soybean S4003 14 to non-transgenic soybeans. Journal of Ecology and Rural Environment 36(3): 367-373 (in Chinese). https://doi.org/ 10.19741/j.issn.1673-4831.2019.0384

Liu J, Zhou B, Yang CY, Li YR, Jiang LX, Zhang MC, Tao B, Qiu LJ (2012) Gene flowing of genetically modified glyphosate-resistant soybean with EPSPS. Soybean Science 31(4):517-521 (in Chinese)

Liu LP, Liu B (2018) Effects of transgenic glyphosate-tolerate soybean on pollen viability. Soybean Science 37(5):736-740 (in Chinese). https://doi.org/10.11861/ j.issn.1000-9841.2018.05.0736

Liu Q, Li XC, Liu ZJ, Li T, Lei BJ (2008) Study on Round up Ready gene move to soybean by Anemophily. Heilongjiang Agricultural Sciences 1:14-16 (in Chinese)

Liu SN, Song XL, Hu YH, Dai WM, Qiang S (2016) Fitness of hybrids between two types of transgenic rice and six Japonica andIndica weedy rice accessions. Crop Science 56:2751-2765. https://doi.org/10.2135/cropsci2015.11.0719

Lu BR, Snow AA (2005) Gene Flow from Genetically Modified Rice and Its Environmental Consequences. Bioscience 55:669-678. https://doi.org/10.1641/0006-3568(2005)055[0669:GFFGMR] 2.0.CO;2 
Mercer KL, Andow DA, Wyse DL, Shaw RG (2007) Stress and domestication traits increase the relative fitness of cropwild hybrids in sunflower. Ecol Lett 10:383-393. https:// doi.org/10.1111/j.1461-0248.2007.01029.x

Mizuguti A, Ohigashi K, Yoshimura Y, Kaga A, Kuroda Y, Matsuo K (2010) Hybridization between GM soybean (Glycine $\max$ (L.) Merr.) and wild soybean (Glycine soja Sieb. et Zucc.) under field conditions in Japan. Environ Biosaf Res 9:13-23. https://doi.org/10.1051/ebr/2010004

Mizuguti A, Oshimura YY, Matsuo K (2009) Flowering phenologies and natural hybridization of genetically modified and wild soybeans under field conditions. Weed Biology and Management 9:93-96. https://doi.org/10.1111/j.14456664.2008.00324.X

Nakayama Y, Yamaguchi H (2002) Natural hybridization in wild soybean (Glycine max ssp. soja) by pollen flow from cultivated soybean (Glycine max ssp. max) in a designed population. Weed Biology and Management 2:25-30. https://doi.org/10.1046/j.1445-6664.2002.00043.x

Ohara M, Shimamoto Y (2002) Importance of genetic characterization and conservation of plant genetic resources: The breeding system and genetic diversity of wild soybean (Glycine soja). Plant Species Biology 17:51-58. https:// doi.org/10.1046/j.1442-1984.2002.00073.x

Palmer RG, Newhouse KE, Graybosch RA, Delannay X (1987) Chromosome structure of the wild soybean. The Journal of heredity 78:243-247. https://doi.org/10.1093/ oxfordjournals.jhered.a110375

Palmer RG, Sun H, Zhao LM (2000) Genetics and cytology of chromosome inversions in soybean germplasm. Crop Sci 40:683-687. https://doi.org/10.2135/cropsci2000.403683x

Renton M, Chauhan BS (2017) Modelling crop-weed competition: Why, what, how and what lies ahead?. Crop Protection 95:101-108. https://doi.org/10.1016/j.cropro.2016.09.003

Singh RJ, Hymowitz T (1988) The genomic relationship between Glycine $\max (\mathrm{L}$.) Merr. and G. soja Sieb. and Zucc. as revealed by pachytene chromosome analysis. Theoretical and Applied Genetics 76:705-711. https://doi. org/10.1007/BF00303516

Singh RJ, Hymowitz T (1985) The genomic relationships among six wild perennial species of the genus Glycine subgenus Glycine Willd. Theoretical and Applied Genetics 71:221-230. https://doi.org/10.1007/BF00252059

Song JS, Kim JW, Im JH, Lee KJ, Lee BW, Kim DS (2017) The effects of single and multiple-weed interference on soybean yield in the far-eastern region of Russia. Weed Sci 65:371-380. https://doi.org/10.1017/wsc.2016.25

Stupar RM (2010) Into the wild:The soybean genome meets its undomesticated relative. Proceedings of the National Academy of Sciences PNAS 107:21947-21948. https://doi.org/10.1073/pnas.1016809108

Vu DT, Velusamy V, Park E (2014) Structure and chemical composition of wild soybean seed coat related to its permeability. Pak J Bot 46:1847-1857

Wang KJ, Li XH (2011) Interspecific gene flow and the origin of semi-wild soybean revealed by capturing the natural occurrence of introgression between wild and cultivated soybean populations. Plant Breeding 130:117-127. https:// doi.org/10.1111/j.1439-0523.2010.01815.x

Wang KJ, Li XH, Liu Y (2012) Fine-scale phylogenetic structure and major events in the history of the current wild soybean (Glycine soja) and taxonomic assignment of semiwild Type (Glycine gracilis Skvortz.) within the Chinese subgenus Soja. J Hered 103:13-27. https://doi.org/10. 1093/jhered/esr102

Wang KJ, Li XH, Yan MF (2014) Genetic differentiation in relation to seed weights in wild soybean species (Glycine soja Sieb. \& Zucc.). Plant Syst Evol 300:1729-1739. https://doi.org/10.1007/s00606-014-0998-8

Wang KJ, Li XH, Zhang JJ, Chen H, Zhang ZL, Yu GD (2010) Natural introgression from cultivated soybean (Glycine max) into wild soybean (Glycine soja) with the implications for origin of populations of semi-wild type and for biosafety of wild species in China. Genet Resour Crop Evol 57:747-761. https://doi.org/10.1007/s10722-009-9513-4

Wang KJ, Takahata Y (2007) A Preliminary comparative evaluation of genetic diversity between Chinese and Japanese wild soybean (Glycine soja) germplasm pools using SSR markers. Genet Resour Crop Evol 54:157-165. https://doi.org/10.1007/s10722-005-2641-6

Wang YS, Ghouri F, Shahid MQ, Naeem M, Baloch FS (2017) The genetic diversity and population structure of wild soybean evaluated by chloroplast and nuclear gene sequences. Biochem Syst Ecol 71:170-178. https://doi.org/ 10.1016/j.bse.2017.02.008

Warwick SI, Beckie HJ, Hall LM (2009) Gene flow, invasiveness, and ecological impact of genetically modified crops. Ann N Y Acad Sci 1168:72-99. https://doi.org/10.1111/j. 1749-6632.2009.04576.x

Wen ZX, Ding YL, Zhao T, Gai JY (2009) Genetic diversity and peculiarity of annual wild soybean (G. soja Sieb. et Zucc.) from various eco-regions in China. Theoretical and Applied Genetics 119:371-381. https://doi.org/10.1007/ s00122-009-1045-y

West AM, Richardson RJ, Arellano C, Burton MG (2010) Bushkiller (Cayratia japonica) growth in interspecific and intraspecific competition. Weed Sci 58:195-198. https:// doi.org/10.1614/WS-09-051.1

Whitney KD, Randell RA, Rieseberg LH (2006) Adaptive introgression of herbivore resistance traits in the weedy sunflower Helianthus annuus. Am Nat 167:794. https://doi. org/10.1086/504606

Yang X, Xia H, Wang W, Wang F, Su J, Snow AA, Lu BR (2011) Transgenes for insect resistance reduce herbivory and enhance fecundity in advanced generations of crop weed hybrids of rice. Evolution Applications 4 672-684 10.1111\%2Fj.1752-4571.2011.00190.x

Yoshimura Y, Mizuguti A, Matsuo K (2011) Analysis of the seed dispersal patterns of wild soybean as a reference for vegetation management around genetically modified soybean fields. Weed Biology and Management 11:210-216. https://doi.org/10.1111/j.1445-6664.2011.00422.x

Zhou S, Sekizaki H, Yang Z, Sawa S, Pan J (2010) Phenolics in the seed coat of wild soybean (Glycine soja) and their significance for seed hardness and seed germination. Journal of Agricultural and Food Chemistry 58:10972-10978. https://doi.org/10.1021/jf102694k

Publisher's Note Springer Nature remains neutral with regard to jurisdictional claims in published maps and institutional affiliations. 